\title{
CLINICAL OUTCOME OF GRAFTLESS SINUS LIFTING
}

\author{
Ramy Ragab Elbeialy*
}

\begin{abstract}
To examine the outcome of graftless sinus floor elevation with simultaneous implant placement.

Patients and methods: 18 implants were inserted with simultaneous implant placement in grafted versus non grafted sinus lifting.

Results: Comparable results were obtained from both groups regarding the quality and stability of the newly formed bone.

Summary and conclusion: Graftless sinus lifting with simultaneous implant placement is a predictable technique.
\end{abstract}

KEYWORDS: Sinus lifting, implant in sinus, graftless sinus lift

\section{INTRODUCTION}

Since the introduction of Osseo integrated implants for treatment of edentulous jaws, it has been possible to reconstruct patients with a sufficient amount of bone without the need for additional procedures. However patients with severe atrophy of the maxillary alveolar process and/or excessively pneumatized maxillary sinus are difficult to treat by conventional implant techniques due to the lack of a sufficient amount of alveolar bone into which implants can be anchored. Bone availability is the key to successful placement of endosseous implants in the posterior maxilla. When the available bone between the maxillary sinus and the alveolar crest is insufficient, increasing this thickness by sinus grafting is necessary to support the required long implants and prosthetic restoration. During recent years the sinus lift or sinus elevation surgical technique has opened up a new way of anchoring endosseous implants despite marked bone reduction. The graft material chosen must provide adequate viable bone to initially stabilize the implant and encourage Osseo integration.Autogenous bone is considered the Gold standard for bone grafting. Morbidity of the donor site is considered a drawback to the use of autogenous bone for implant surgery. A limitation for the use of bone substitute for this procedure is their poor regenerative capacity as compared with autogenous bone. ${ }^{(1,2)}$

\section{Review of literature}

The problems related to implants placement in the posterior maxillary region include lack of vertical and /or bucco-lingual dimension due to

* Department of Oral and Maxillofacial Surgery Department, Cairo University 
alveolar ridge resorption, antral pneumatisation, poor bone quality, difficult surgical and prosthetic access and high bite force requirement. ${ }^{(3,4)}$

Unfortunately, one of the most problematic regions has been the posterior maxilla in having not only poor bone density, but also lack of adequate bone height as a result of sinus pneumatisation and consequently an inadequate alveolar bone height below the maxillary sinus is a frequent anatomical restriction for the prosthetic rehabilitation of the upper jaw with endosseous implants. ${ }^{(5,6)}$

Different surgical techniques have been proposed to increase the height of crestal bone available for implant placement. ${ }^{(7,8)}$ However, in addition to the quantity of bone, a further factor requiring consideration in relation to the osseous anchoring of implants is bone quality. There is often no cortical bone in the posterior region of the maxilla, and frequently the cancellous bone is of only low density. These facts explain the inferior long-term success rates for implants placed in the maxilla in comparison to the mandible..$^{(9,10)}$

The problems of implant placement in the posterior maxilla have been solved by the introduction of the sinus floor elevation. The indication for sinus grafting procedures is at hand when conventional implant treatment is impossible to perform due to reduced bone height and width below the maxillary sinus. Different studies exhibited a crestal bony height varying between 1 $\mathrm{mm}$ and $5.5 \mathrm{~mm}$ with a mean value of only $2.5 \mathrm{~mm}$.) If the alveolar bone volume is sufficient to achieve initial implant stability and the grafted bone only engages the apical part of the implant, the survival rates are expected to increase significantly. In cases with no more than 1 to $2 \mathrm{~mm} /$.bone height, there is an obvious risk that there will be micromobility in the bone transplant with its implants. ${ }^{(11)}$

Lundgren et al ${ }^{(11)}$ recently evaluated a surgical technique in 10 patients where an open controlled sinus membrane lift procedure with simultaneous placement of 19 implants was performed. A bony window was cut out the lateral maxillary sinus wall and repositioned after implant placement, thus allows the blood clot and later on bone to form in an undisturbed compartment around the implants. The available height at time of surgery was 6 to $10 \mathrm{~mm}$. Patients were followed up for 1 year and after installation of implants. Evidence of bone formation around all installed implants was registered.

In a study conducted by Kusiak $\mathbf{J}$ et al, ${ }^{(12)}$ on 20 patients with 44 implants were sinus floor elevation was performed with simultaneous implant placement without any graft material. The subantral bone remaining was $\leq 6 \mathrm{~mm}$. All implants inserted were long implants 13 to $15 \mathrm{~mm}$ long. With this technique, new bone was formed without the use of any graft material on and around the implants. Instead of using autogenous bone or allografts for augmenting the sinus floor and later placing the implants, implants are inserted simultaneously and left to heal for 4 to 6 months. As a consequence of the data presented recently in the literature, the use of a graft material for augmenting the sinus floor has decreased substantially during the last 2 years in many dental offices worldwide.

Chen et al in $2007^{(13)}$ evaluated the status of bone in patients subjected to maxillary sinus lifting and immediate implant placement with no graft material. In all 47 cases who received implants immediately after the lateral approach of the trap door window procedure to create a maxillary sinus lift without bone grafting, radiographic assessment proved that bone formation was evident to be filling the gap in 9 months post-surgical. No patients developed sinusitis or any other complications leading to implant loss. All 47 fixtures healed well, no infection or implant mobility was observed during initiation of loading force from the prosthetic components from 9 month after implant placement up. The height of the primary edentulous ridge below the sinus floor was $7.5 \pm 2.0 \mathrm{~mm}$.Increase in lifted sinus bone height ranged from 3-7 mm. Through a minimum of 2 years follow up, the success rate was $100 \%$ in all 47 implants. 
In 2014, Pinchasov $G$ et al published his systematic review including 19 studies related to sinus membrane osteogenic potential, histologic and radiographic evidence of bone formation following graftless sinus lifting. $100 \%$ of the reviewed articles showed increased bone formation and high implant success rate related to graftless sinus lifting. ${ }^{(14)}$

\section{Aim of study}

The aim of the study is to analyse the change in bone density and bone formation around dental implants placed in partially dentate maxilla simultaneously with maxillary sinus elevation with and without autogenous bone graft.

\section{PATIENTS AND METHODS}

Eighteen implants were inserted in twelve cases of both sexes indicated for maxillary sinus floor augmentation and implantation, were carefully selected from the outpatient clinic, Oral and Maxillofacial Surgery Department, Cairo University hospital. All cases were performed in the minor surgery clinic, Oral and maxillofacial surgery department, Cairo University. The ages of the selected cases ranged from 35 to 55 years, mean age 45 years. The male: Female Ratio was 1:1.

Each patient in this study was partially edentulous in posterior maxilla and required a fixed restoration. Cases with limited bone height below the floor of the maxillary sinus, secondary to sinus pneumatisation were particularly selected for prosthetic reconstruction.

All the patients were entailed about the study and they gave their approval to participate on written consent.

\section{Criteria for selection of patients}

1) All patients were in a good general health with no systemic, immunologic or debilitating diseases that could affect normal bone healing.
2) All selected patients were non-smokers and non-alcoholics.

3) Patients were free from T.M.J troubles, abnormal oral habits such as bruxism.

4) Remaining natural teeth had good periodontal tissue support and occlusion showed sufficient inter arch space for the future prosthesis.

5) The edentulous ridges were covered with optimum thickness of mucoperiosteum with no signs of inflammation, ulceration or scar tissue.

6) On the local level, patients with maxillary sinus diseases, former sinus surgery like Caldwell luc operations, sever sinus floor convolutions (sinus septa); extremely narrow sinuses and unfavourable inter maxillary relationship were excluded.

7) Site analysis was performed with panoramic radiography in all cases. When panoramic radiography did not reveal a clear or compromised image, CT-scan was made.

8) Sinus grafting was planned in those cases where a minimum bone height of $4 \mathrm{~mm}$ was available.

\section{Patient Examination}

\section{Medical Evaluation}

Complete medical history was obtained from each patient to evaluate the patient general and specific medical history. Generally, we excluded all diseases that may cause poor bone turnover or poor bone metabolism in order not to affect the future bone healing or jeopardize the implants and graft success.

\section{Laboratory Investigations}

Complete blood count (CBC) and coagulation profiles were done for each patient to determine any haematological disorders. 


\section{Dental Evaluation}

Complete dental history were obtained from each patient to evaluate the patients' past dental history, asking about their habits as bruxism, biting on hard objects, any previous complications during dental extraction or local anaesthesia, and their compliance in pervious dental treatment procedures were all considered.

All cases were selected to have extractions in the posterior maxilla not less than two years from the date of surgery.

\section{Clinical Examination}

\section{Extra-Oral Examination}

Inspection and palpation, were done for each patient, for extra-oral sites such as temporomandibular joint (TMJ), facial muscles and masticatory muscles, cervico-facial lymph nodes and maxillary sinus.

\section{Intra-Oral Examination}

The condition of the existing dentition as well as periodontal condition was evaluated to determine the need for any pre surgical restorative or periodontal treatment.

Examination of both hard and soft tissues was done through inspection and palpation. Mucoperiosteum covering the posterior maxillary edentulous ridge area was inspected for any signs of inflammation, ulceration or scar formation. Posterior mandibular teeth opposing the posterior maxillary edentulous area were inspected. Cases with super-erupted posterior mandibular teeth with no enough inter arch space were excluded.

The mandibular anterior region was examined to determine the condition of the lower anterior teeth and surrounding alveolar bone to determine the fitness of the symphysial region as the donor site.

\section{Radiographic Examination:}

\section{Panoramic radiographs:}

Pre-operative panoramic radiograph was obtained for each patient to determine the residual alveolar bone height. It also helps for detection of any small remaining roots or bony pathoses in the posterior maxillary region as well as the symphysial region. Any patients with bony pathoses were excluded from the study. Panoramic radiographs were used to determine the available bone in the symphysis region to avoid trauma to lower anterior teeth. Maxillary sinus was examined for any opacities or prominent sinus septa.

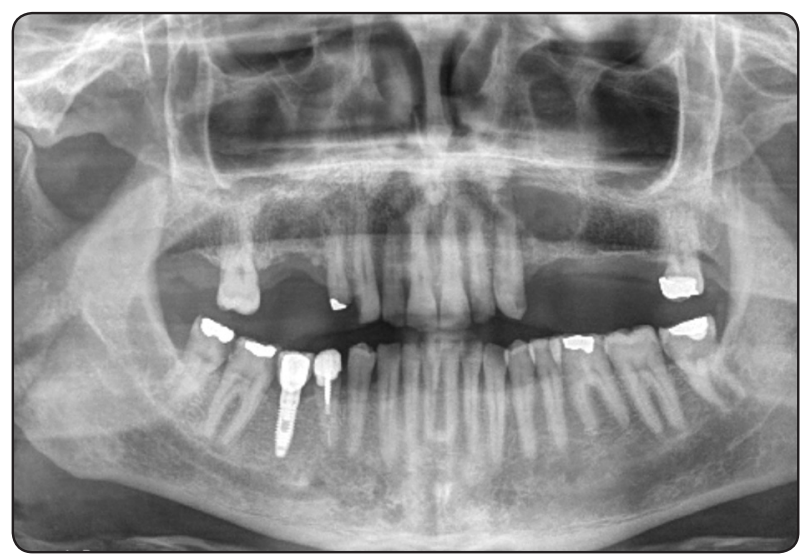

Fig. (1): Showing preoperative panoramic radiograph of case 1.

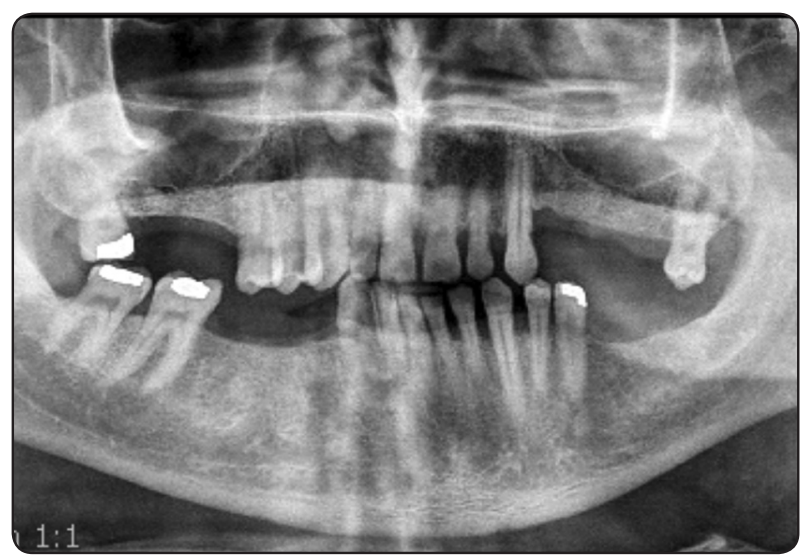

Fig. (2): Showing preoperative panoramic radiograph of case 2. 


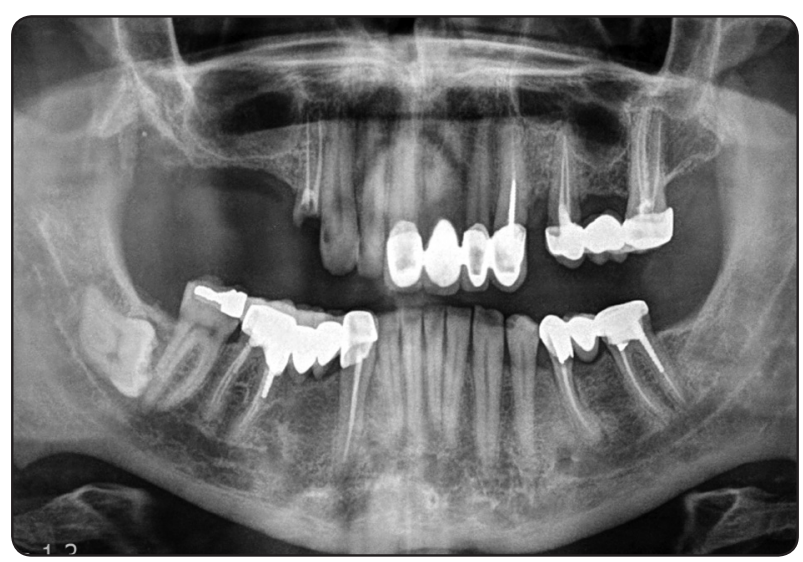

Fig. (3): Showing pre operative panoramic radiograph of case 3.

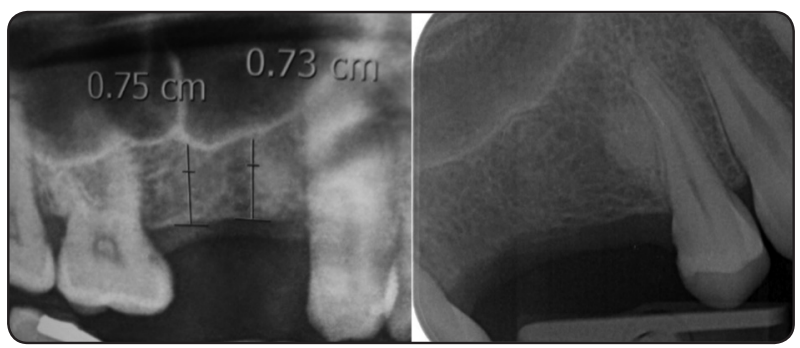

Fig. (4): Showing pre operative periapical radiographs using direct digital radiography.

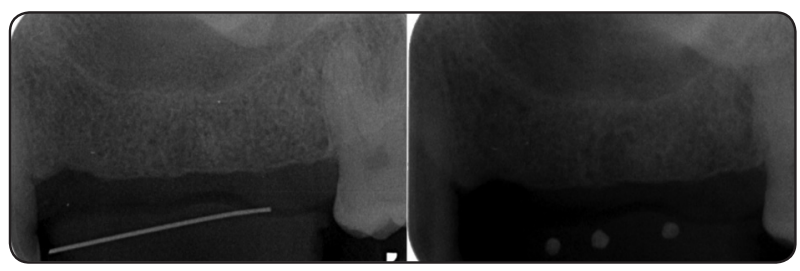

Fig. (5): Showing pre operative periapical radiographs using direct digital radiography.

\section{Patients Grouping:}

Cases included in this study were divided into two groups:

Control Group: Consist of six patients subjected to sinus floor elevation with simultaneous implants placement and autogenous bone harvested from the symphysial region was used as bone graft.

Active group:Consists of six patients subjected to sinus floor elevation with simultaneous implant placement without bone graft. Sinus membrane was left to fall under its own weight on the implants. The gap between the sinus membrane and the implants was left to be filled with blood.

TABLE (1) Control group (Autogenous bone graft)

\begin{tabular}{|c|c|c|c|}
\hline $\begin{array}{c}\text { Case } \\
\text { Number }\end{array}$ & Tooth Restored & $\begin{array}{c}\text { Implant } \\
\text { Length }\end{array}$ & $\begin{array}{c}\text { Implant } \\
\text { Diameter }\end{array}$ \\
\hline $\mathbf{1}$ & First Premolar & 14 & 4.8 \\
\hline $\mathbf{2}$ & Second Premolar & 14 & 4.8 \\
\hline $\mathbf{3}$ & Second premolar & 14 & 4.8 \\
\hline $\mathbf{4}$ & First molar & 14 & 4.8 \\
\hline $\mathbf{5}$ & First premolar & 14 & 3.7 \\
\hline $\mathbf{6}$ & Second premolar & 14 & 4.8 \\
\hline $\mathbf{7}$ & First molar & 14 & 4.8 \\
\hline $\mathbf{8}$ & Second premolar & 14 & 4.8 \\
\hline $\mathbf{9}$ & First molar & 14 & 4.8 \\
\hline
\end{tabular}

TABLE (2) Active group (No bone graft):

\begin{tabular}{|c|c|c|c|}
\hline $\begin{array}{c}\text { Case } \\
\text { Number }\end{array}$ & Tooth Restored & $\begin{array}{c}\text { Implant } \\
\text { Length }\end{array}$ & $\begin{array}{c}\text { Implant } \\
\text { Diameter }\end{array}$ \\
\hline $\mathbf{1}$ & Second premolar & 14 & 4.8 \\
\hline $\mathbf{2}$ & First molar & 14 & 4.8 \\
\hline $\mathbf{3}$ & First premolar & 12 & 3.7 \\
\hline $\mathbf{4}$ & Second Premolar & 14 & 4.8 \\
\hline $\mathbf{5}$ & First molar & 14 & 4.8 \\
\hline $\mathbf{6}$ & First premolar & 14 & 4.8 \\
\hline $\mathbf{7}$ & First molar & 14 & 4.8 \\
\hline $\mathbf{8}$ & Second premolar & 14 & 3.7 \\
\hline $\mathbf{9}$ & First molar & 12 & 3.7 \\
\hline
\end{tabular}

\section{Implant System:}

Zimmer Swiss Plus dental implant system was used in all cases in the current study. It is only available in two diameters: $3.7 \mathrm{~mm}$ and $4.8 \mathrm{~mm}$ in straight and tapered forms.

\section{Surgical procedures:}

\section{Pre operative preparation:}

\section{Construction of radiographic stent:}

An alginate impression was taken to the patient and a plaster model was poured. A diagnostic wax 
up was performed and a hard acrylic template was fabricated.

On the plaster model, the fabricated acrylic bite block was fitted to the edentulous alveolar ridge from one side, and fitted to the film holder on the opposite side with an occlusal slot in the acrylic resin ensuring the same standardized position for every radiograph. Using a small round bur, several holes were drilled horizontally in bucco-lingual direction in the acrylic bite block where gutta-percha points were inserted to be used as fixed reference points. The gutta-percha points were then fixed using pink wax or self-curing acrylic resin.

The image plate was inserted into its disposable sleeve \& mounted on the film holder ${ }^{*}$ which is connected to the aiming ring through a metallic bar.

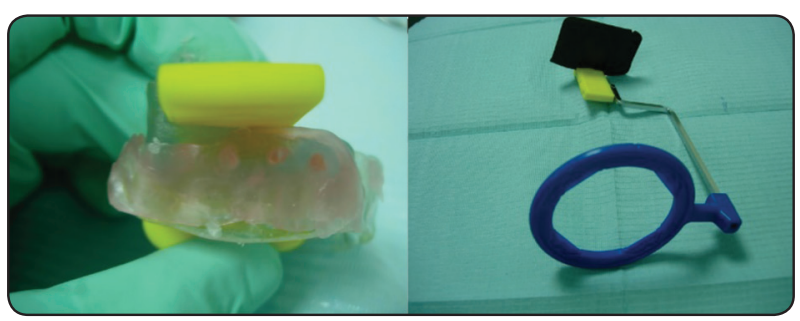

Fig. (6): Showing radiographic stent and film holder

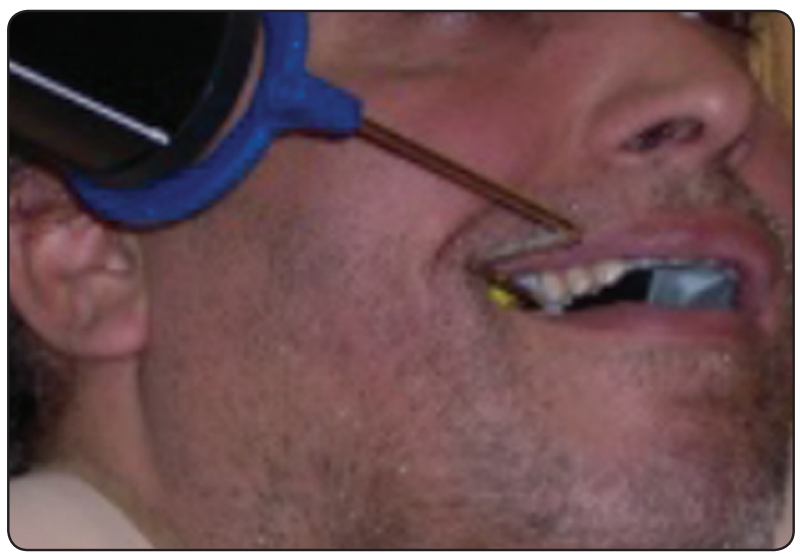

Fig. (7): Showing patient with film holder in place.

* Rinn XCP. Dentsply limited. United Kingdom

\section{Mouth preparation}

Preoperative medication was taken:

A- Prophylactic antibiotic (Augmentin $1 \mathrm{gm}$ capsule) two times daily starting one day prior to surgery and continue for 5 days after surgery.

B- Mouth rinse Oraldene, $0.12 \%$ chlorohexidine gluconate (McNeil Products Ltd, Maidenhead, Berkshire, UK) three times daily.

\section{Surgical procedure}

It consists of three stages:

\section{Sinus lifting.}

2. Harvesting autogenous bone graft from symphysis of the mandible.

3. Bone grafting and conventional implantation.

\section{Sinus lifting technique:}

After local infiltration anaesthesia of the region to be grafted an incision was made palatal to the ridge crest in the edentulous area to be treated, this incision was continued in to buccal vestibule several millimetres anterior and posterior to the graft area. A superiorly based full thickness mucoperiosteal flap was elevated to expose the lateral wall of the maxilla. A no. 8 round diamond bur (sinus bur) was

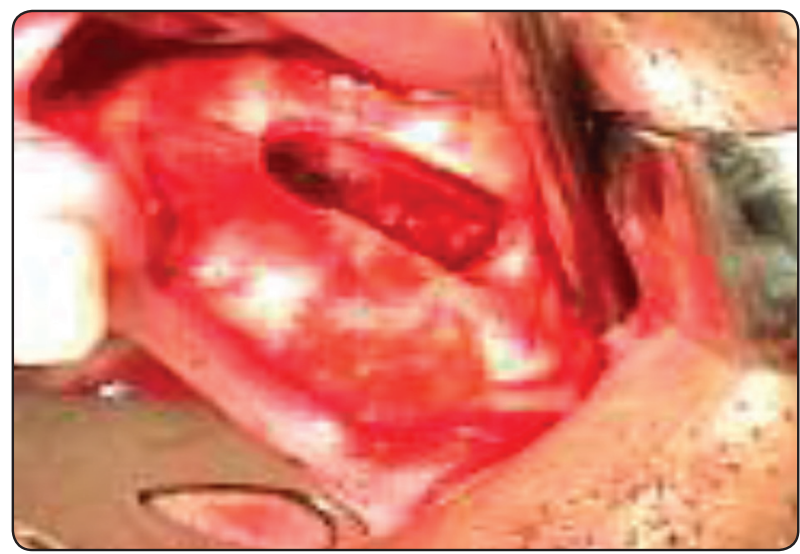

Fig. (8): Showing the lateral window for approaching the sinus membrane. 
used in the straight hand piece, at approximately 40,000 rpm with copious irrigation, to delineate the outline of the antrum on the lateral wall of the maxilla. Care was taken not to penetrate the sinus membrane.

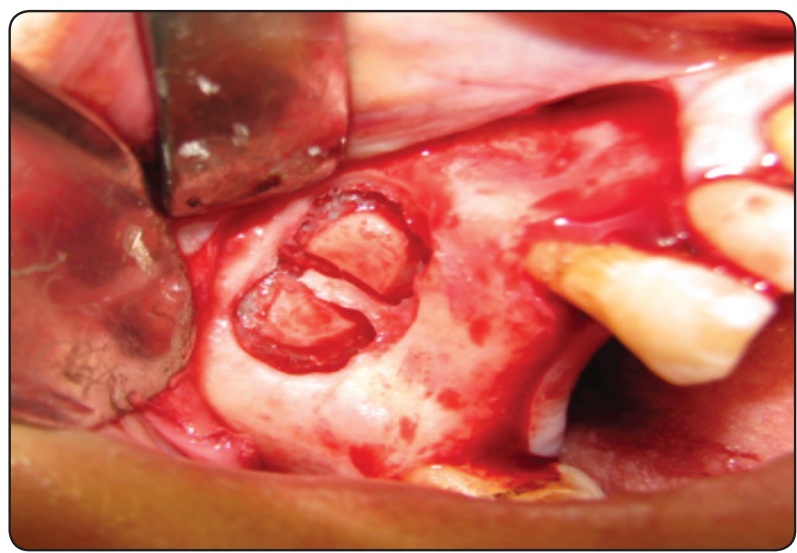

Fig. (9): Showing the design of the lateral window in case of maxillary sinus septum.

Once the outline was completed, special elevator (surgical sinus freer*) was used to gently push the sinus membrane inward, and at the same time the trap door was in fractured. As the dissection continued, the membrane was elevated from the floor, lateral wall, medial wall and antero- posteriorly to provide a large compartment for graft placement. If any tears were visualized in the membrane, collagen membrane was placed below the lifted sinus membrane to isolate the lower compartment where implants and graft are to be placed.

Harvesting autogenous bone graft from symphysis of the mandible.

After local infiltration anaesthesia to the region of the symphysis intraorally, a vestibular approach was made. The incision was made in the mucosa between the canine teeth areas at least $1 \mathrm{~cm}$ beyond the mucogingival junction. A full thickness mucoperiosteal flap was reflected toward the base of the mandible to the level of pogonion, leaving

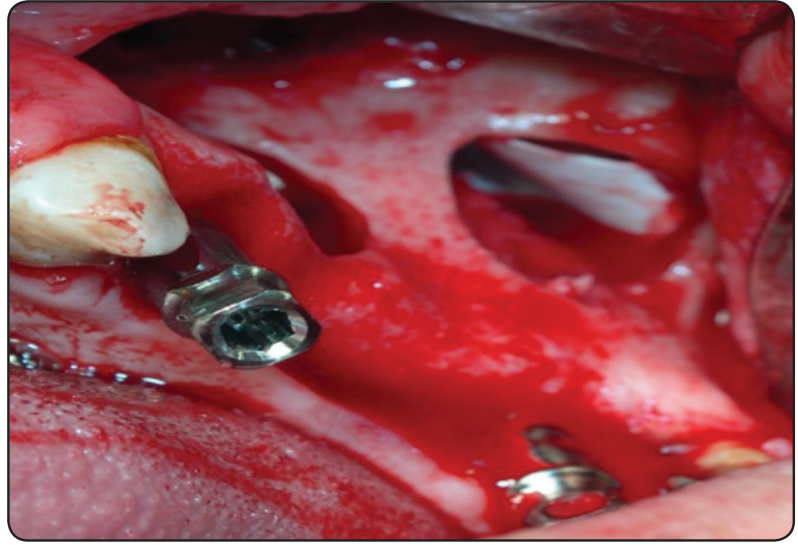

Fig. (10): Showing a collagen membrane inserted under the lifted sinus membrane to cover small sinus membrane perforation

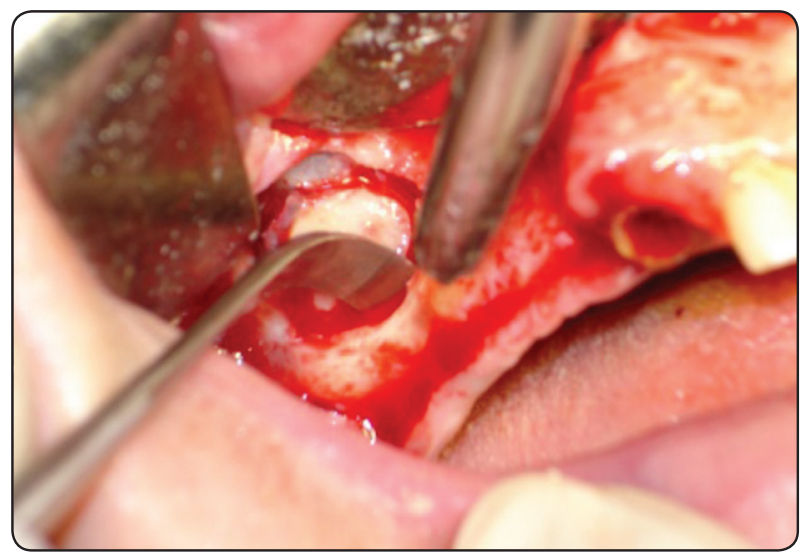

Fig. (11): Showing surgical freer lifting the maxillary sinus membrane.

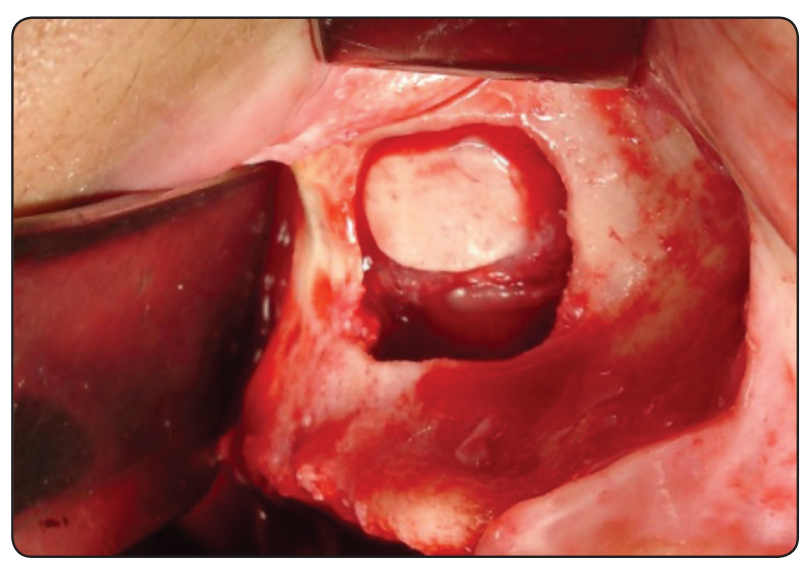

Fig. (12): Showing the sinus membrane after being freed from the surrounding bone.

*Sinus freer by Aesculap number P00 451, 453455. 


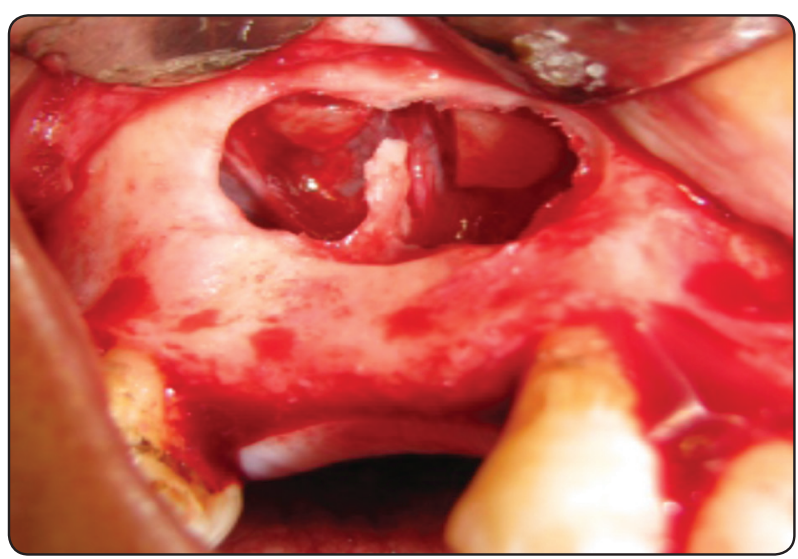

Fig. (13): Showing the sinus membrane elevated in case of a sinus septum.

the most facial aspect of the periosteal attachment intact. After the exposure of the labial wall of the mandible at symphysis area, the osteotomy for the graft harvest was planned. Dimensions of the block were determined by the size of the defect.

The osteotomies were performed with a no. 10 fissure bur was used in the straight hand piece, at approximately 40,000 rpm under copious irrigation, to outline the dimension of the graft needed. Care was taken not to injure the mental nerve during retraction or elevation of the tissues also avoiding trauma to the roots of lower anterior by taken graft away from the apex of the mandibular teeth by 3-5 $\mathrm{mm}$. Then by using trephine bur in a surgical hand piece under copious saline irrigation and / or bone chisel and hammer.

The depth of the osteotomies extended completely through the outer cortex. A bone chisel was tapped along the osteotomy, with the exception

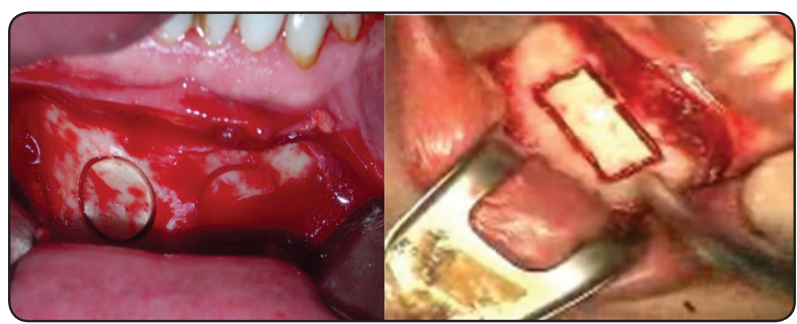

Fig. (14): Showing harvesting bone from thesymphysis region. of the inferior border, to deliver the graft. Additional cancellous bone was procured with a rongeur or chisel. Bone wax or haemostatic dressing (collagen or gelatine sponge) was placed into areas of heavy osseous bleeding after bone harvest, and. The soft tissue superior to the initial incision was elevated to reduce tension on the flap from oedema, and a twolayered closure was used.

\section{Recipient Site}

The proposed recipient site for the graft was exposed prior to graft harvest in all cases. In this manner, the dimension and morphology of the bony defect were measured, and minimal time elapsed between graft harvest and placement.

\section{Simultaneous implantation by conventional method}

An atraumatic technique of bone preparation was done. Twist drills of increasing size rotating at no more than $1500 \mathrm{rpm}$ and cooled with copious external normal saline irrigation are used to prepare the bone. A round bur is used to mark the implant sites in the bone after reflecting the mucoperiosteum; stents prepared presurgically can be used to help determine the ideal location and angulation for the implants.

Drills of increasing diameter $(2 \mathrm{~mm}, 2.8,3.4$ and $3.8 \mathrm{~mm}$ ) were used to make the osteotomy. Implant was then inserted in place in the prepared osteotomy while the sinus freer was held in place carrying the sinus membrane upwards to avoid any unvisualized tension from the implant on the sinus membrane

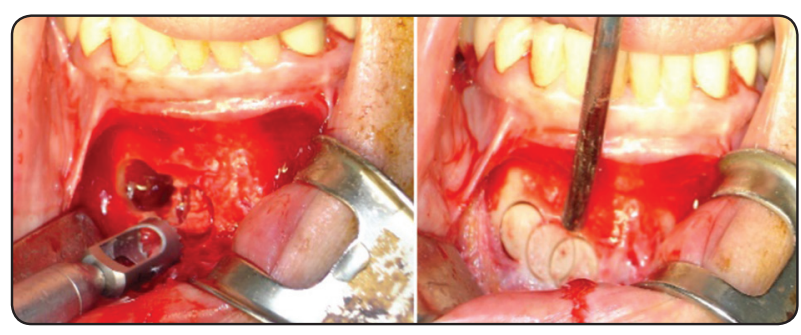

Fig. (15): Showing harvesting bone from the symphysial region using trephine burs. 


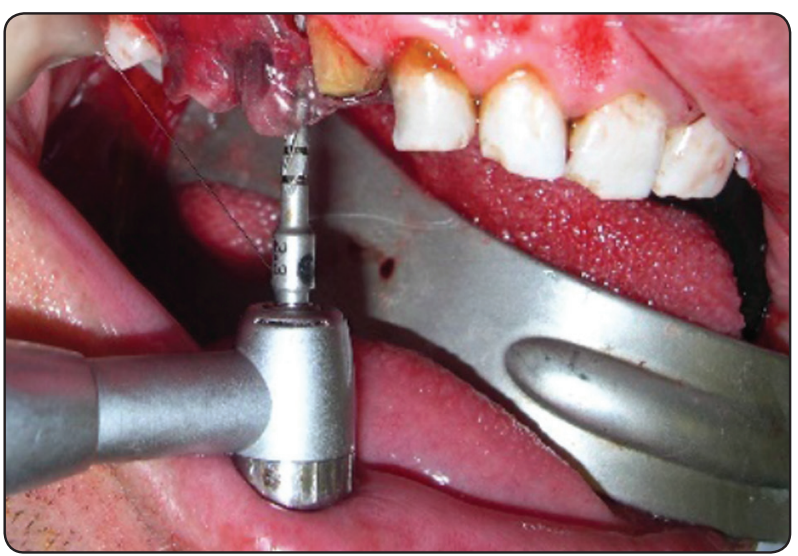

Fig. (16): Showing preparation of the implant bed using surgical stents

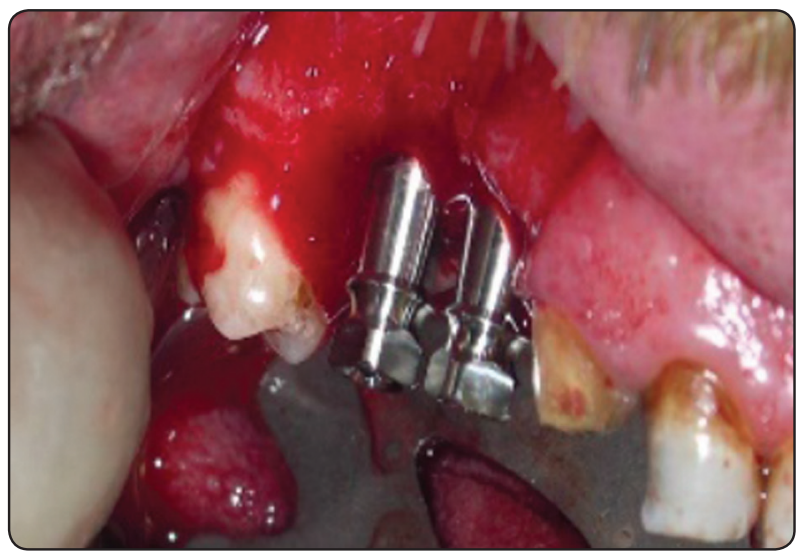

Fig. (17): Showing implants inserted in place.

\section{In the control group:}

The bone graftwas then milled using manual bone mill and packedaround the implants.

\section{In the active group:}

No graft was placed. The implants were inserted in position and the sinus membrane was left to fall under its own weight on the implants.

The defect created between the sinus membrane and the original bony sinus floor is left to be filled with blood. The lateral window is then covered by a resorbable collagen membrane to allow for a stable undisturbed blood clot to form bone. The periosteum at the base of the flap was carefully incised to allow stretching of the mucosa and tension-free adaptation of the wound margins

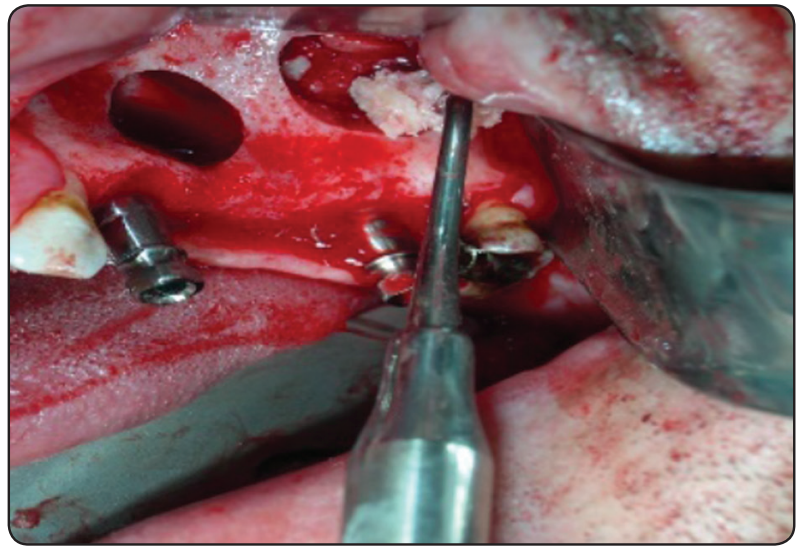

Fig. (18): Showing particulated bone packed into the maxillary sinus

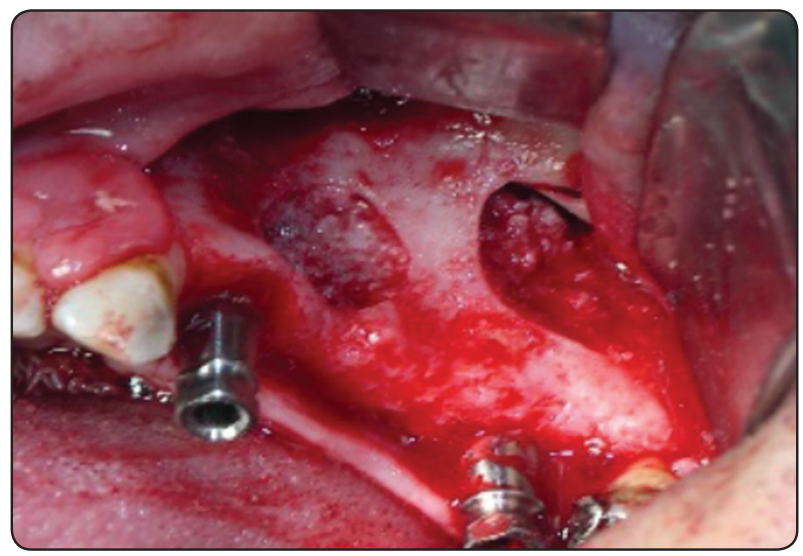

Fig. (19): Showing autogenous bone graft packed around the implants inside the sinus.

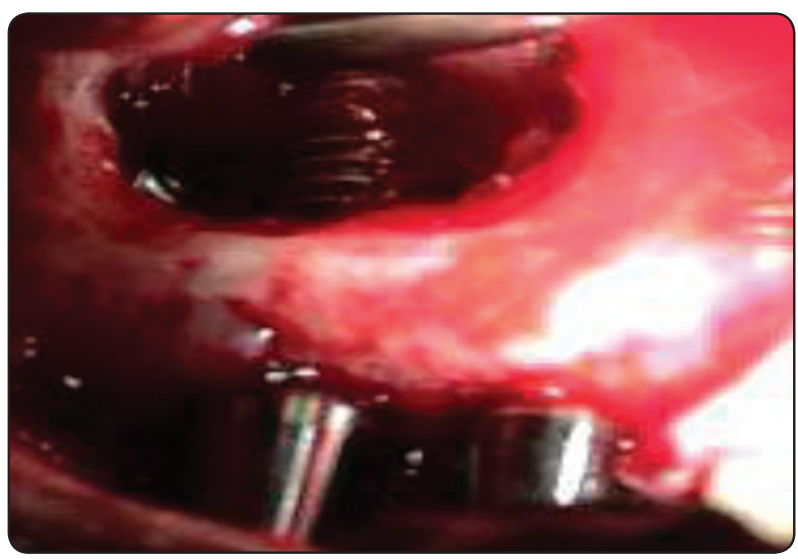

Fig. (20): Showing implants placed with no graft (Tent technique) 
Following the initial healing phase, six months postoperatively, either excision or incision of the mucoperiostium overlying the implant heads and abutments screwed in place. Two weeks later, fabrication of porcelain fused to metal crowns was performed.

\section{Medications and postoperative care:}

a) Prophylactic antibiotic* starting one day prior to surgery and continuing until 5 day post surgical.

b) Mouth rinsing" with (Oraldene 0.12\%)** chlorohexidine gluconate three times daily preoperatively and for ten days postoperatively.

c) Steroids ${ }^{* * *}$ were used to control the amount of swelling, patients received $8 \mathrm{mg}$ epidrone intraoperatively and two $4 \mathrm{mg}$ doses postoperatively IV or IM

d) Nasal drops decongestant ${ }^{* * * *}$ was taken three times daily for ten days, also analgesics ${ }^{* * * * *}$ three times daily for 3-5 days postoperatively.

e) The sutures were removed after 7 days.

\section{Follow up examinations:}

\section{1- Clinical evaluation:}

Patients were evaluated for:

a) Sign and symptoms of postoperative pain, sinus perforation and infection, bleeding nose and dehiscence of the wound or local inflammation

b) Postoperative complications of donor site:

- Altered sensation of lower anterior teeth (symptomatic).

- Altered sensation of lower lip and chin (symptomatic)
Altered sensation of the upper lip (symptomatic)

- Postoperative oedema

\section{Radiographic Evaluation:}

\section{Periapical Radiographs:}

Digital intraoral periapical radiography with paralleling technique was performed immediate, 3 months, 6 months and 9 months postoperatively according to the patient grouping for measurement of bone density changes and analysis. All digital radiographs were taken with the same machine and the same parameters to provide standardization of images.

\section{Digital intraoral periapical radiography:}

Standardized periapical radiography was achieved through the use of digital periapical radiography with paralleling technique utilizing the acrylic bite block fabricated before surgery. The image plate was inserted into its disposable sleeve $\&$ mounted on the film holder which is connected to the aiming ring through a metallic bar. The patient was instructed to remove any metallic objects that may cast radiopaque shadows on the radiograph such as partial denture or eye glasses or any other metal appliances in the head and neck area.

The patient was instructed to wear a lead apron for radiation protection. The position of the acrylic bite block was checked in the patient's mouth. The image plate/film holder assembly were connected to the acrylic bite block and then fixed in place in the patient's mouth. The long cone of the intraoral x-ray machine ${ }^{* * * * *}$ was adjusted to fit into the aiming ring of the film holder and the patient was asked not to move. The dose of x-ray was always fixed for the

\footnotetext{
*Augmentin $1 \mathrm{gm}$ film coated tablets.Manufactured by Novartis pharma, Egypt.

*** Oraldene contains chlorohexidinehydrochloride $125 \mathrm{mg}$ in each $100 \mathrm{ml}$ solution.Manufactured byEDCO, Egypt.

***Epidrone.*mg Hydrocortisone, lipid soluble steroidform, manufactured by N.H. pharma, Egypt.

****Afferin nasal drops.Decongestant. 3 times daily.Manufactured by Novarts, Egypt.

***** Orix 70, $70 \mathrm{KV}, 8 \mathrm{~mA}$, Italy.
} 


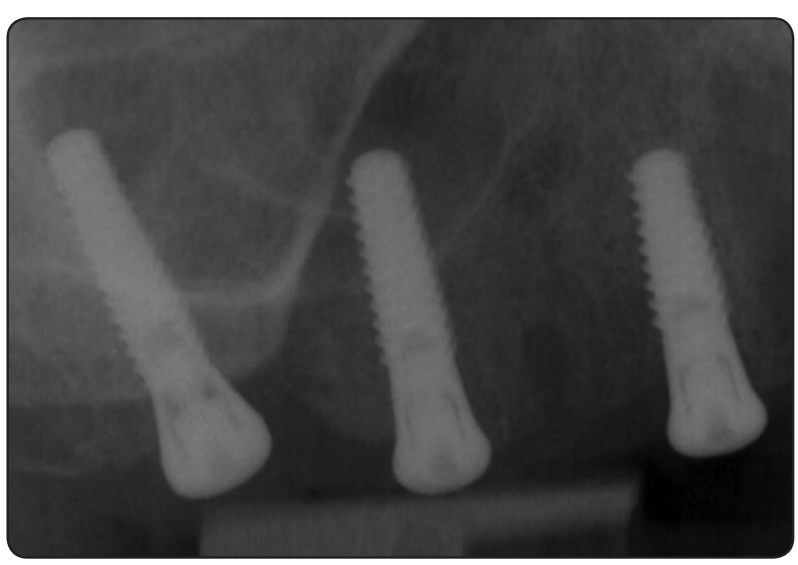

Fig. (21): Showing post operative periapical radiograph using direct digital radiography.

same patient in all radiographs using the same x-ray machine. The image plate was inserted in the laser scanner to obtain a digital image on the monitor of the workstation for analysis.

Linear radiodensitometric radiographic analysis of the digital image was performed using the Digora software* through automatically calculating the mean grey shade values on 3 lines extended mesial, distal and apical to the apical part of the implant extending under the lifted maxillary sinus from fixed reference points drawn directly on the images.The mean density of pixels within the area was recorded. Results were displayed as numerical statistical information.

The recorded measurements were investigated through further statistical analysis and the difference in the mean values showed the changes in healing of the bony defects.

\section{Statistical analysis}

Data were presented as mean and standard deviation (SD) values. Data were explored for

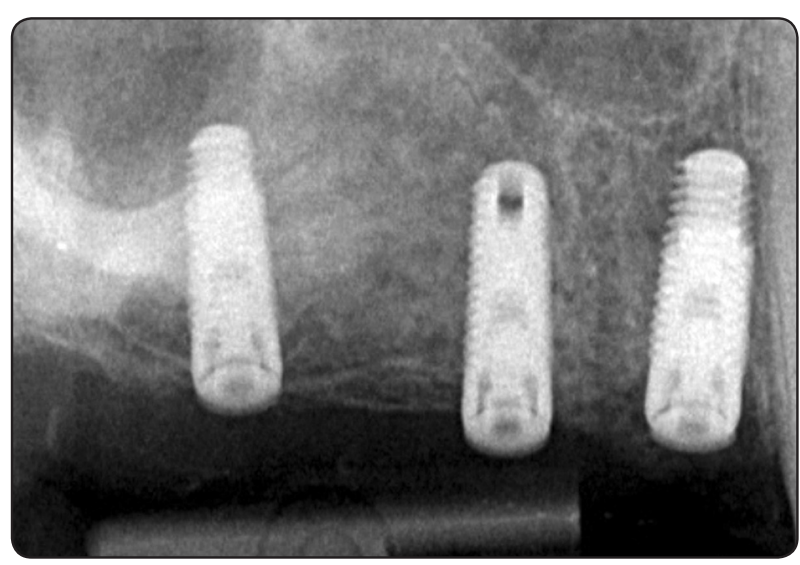

Fig. (22): Showing post operative periapical radiograph using direct digital radiography.

normality using Kolmogorov-Smirnov test. Exploration of data revealed that bone density measurements were normally distributed (parametric data). Student's test was used to compare between the two groups. Paired t-test was used to study the changes by time within each group.

The significance level was set at $P \leq 0.05$. Statistical analysis was performed with SPSS $16.0^{\circledR}$ (Statistical Package for Scientific Studies) for Windows.

\section{RESULTS}

Data have been collected from 12 subjects, aged 35-55 years with mean age of 45 years and male: female ratio of 1:1.

Comparison between the changes in bone density within members of each group separately and between the two groups in terms of mean and standard deviation was performed.

\footnotetext{
* Digora for windows v 1.51 Soredex-Finndent, Finland () SPSS, Inc., Chicago, IL, USA.
} 


\section{Tests of normality}

Table (3): Results of Kolmogorov-Smirnov test of normality.

\begin{tabular}{|c|c|c|c|}
\hline \multirow{2}{*}{\multicolumn{2}{|c|}{ Group }} & Control & Active \\
\hline & & P-value & P-value \\
\hline \multirow{4}{*}{ 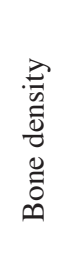 } & Immediate & 0.200 & 0.200 \\
\hline & 3 months & 0.200 & 0.200 \\
\hline & 6 months & 0.152 & $0.019 *$ \\
\hline & 9 months & 0.200 & 0.164 \\
\hline
\end{tabular}

\section{*: Significant at $P \leq 0.05$}

Test of normality results indicate that density data are normally distributed (parametric data).

\section{Comparison between the two groups}

TABLE (4): Mean, standard deviation (SD) values and results of Student's t-test for comparison between bone density of the two groups

\begin{tabular}{|c|c|c|c|c|c|}
\hline \multirow{2}{*}{$\begin{array}{c}\text { Group } \\
\text { Period }\end{array}$} & \multicolumn{2}{|c|}{ Control } & \multicolumn{2}{c|}{ Active } & \multirow{2}{*}{ P-value } \\
\cline { 2 - 5 } & Mean & SD & Mean & SD & \\
\hline Immediate & 131.2 & 25.5 & 95.1 & 21.4 & $0.005^{*}$ \\
\hline 3 months & 105.6 & 24.3 & 110.1 & 18.9 & 0.665 \\
\hline 6 months & 95.8 & 19.6 & 125.1 & 15.6 & $0.003^{*}$ \\
\hline 9 months & 115.1 & 23.8 & 141.4 & 25.3 & $0.037^{*}$ \\
\hline
\end{tabular}

\section{*: Significant at $P \leq 0.05$}

Immediately post-operative, the mean bone density of control group showed statistically significantly higher value than Active group.

After 3 months, there was no statistically significant difference between the two groups.

After 6 months, the mean bone density of active group showed statistically significantly higher value than control group.
After 9 months, the mean bone density of active group showed statistically significantly higher value than control group.

This is due to the continued bone formation in the active group. In fact, the extensive resorption that took place in the autogenous bone graft (control group) during the first six months is responsible for the decreased bone density in this group at nine months post surgical. On the other hand, the active group was only undergoing bone formation in the active group from the beginning.

\section{Changes by time in each group}

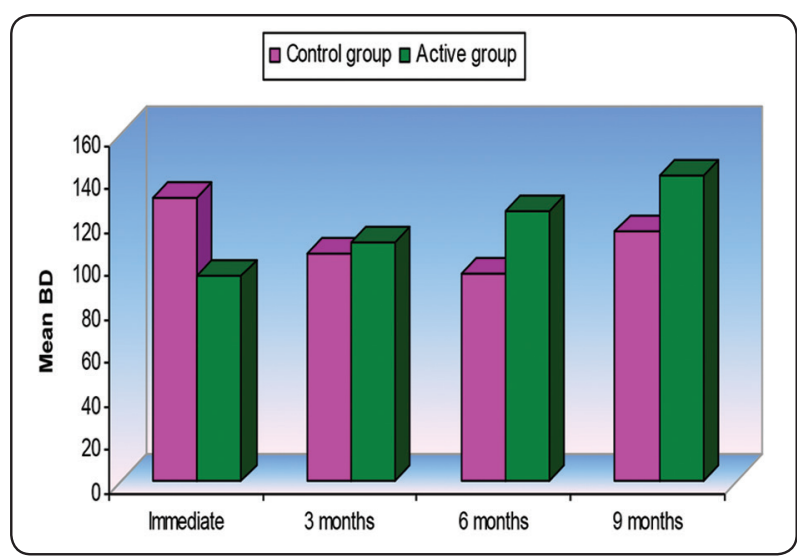

Fig. (23): Bar Chart comparing the change in bone density between the two groups

TABLE (5): Mean differences, standard deviation (SD) values and results of paired t-test for the changes by time within control group

\begin{tabular}{|c|c|c|c|}
\hline Period & $\begin{array}{c}\text { Mean } \\
\text { difference }\end{array}$ & SD & P-value \\
\hline Immediate - 3 months & 25.7 & 6.6 & $<0.001^{*}$ \\
\hline 3 months - 6 months & 9.8 & 8.4 & $0.008^{*}$ \\
\hline 6 months - 9 months & -19.3 & 5.9 & $<0.001^{*}$ \\
\hline Immediate - 6 months & 35.4 & 12.4 & $<0.001^{*}$ \\
\hline 3 months - 9 months & -9.5 & 7.7 & $0.006^{*}$ \\
\hline
\end{tabular}

*: Significant at $P \leq 0.05$ 


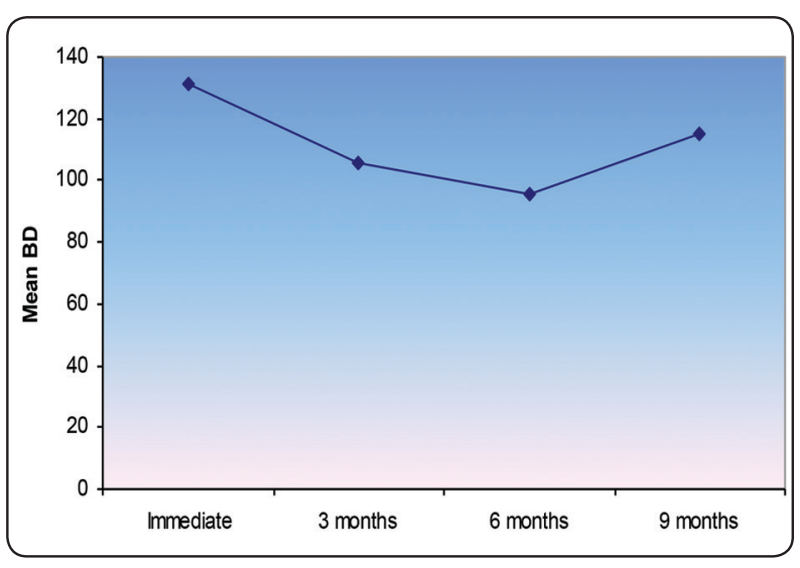

Fig. (24): Graph showing the change in bone density within the control group.

After 3 months, there was a statistically significant decrease in mean bone density. This is explained by the resorption that take place in the autogenous bone graft.

From 3 months - 6 months, there was a statistically significant decrease in mean bone density. This is due to the extended remodelling that take place in the autogenous bone graft.

From 6 months - 9 months, there was a statistically significant increase in mean bone density. This is due to the stabilization of the autogenous bone.

After 6 months, there was a statistically significant decrease in mean bone density. This is due to the extended remodelling that takes place in the autogenous bone graft.

From 3 months-9 months, there was a statistically significant increase in mean bone density. In fact this clarifies that the gross resorption that take place in the autogenous bone graft is during the first three months post surgical, then stabilization start to take place.

TABLE (6): Mean differences, standard deviation (SD) values and results of paired t-test for the changes by time within active group

\begin{tabular}{|c|c|c|c|}
\hline Period & $\begin{array}{c}\text { Mean } \\
\text { difference }\end{array}$ & SD & P-value \\
\hline Immediate -3 months & -15 & 10.1 & $0.002^{*}$ \\
\hline 3 months -6 months & -15 & 10.4 & $0.002^{*}$ \\
\hline 6 months -9 months & -16.3 & 16.6 & $0.019^{*}$ \\
\hline Immediate -6 months & -30 & 17.7 & $0.001^{*}$ \\
\hline 3 months -9 months & -31.3 & 20.1 & $0.002^{*}$ \\
\hline
\end{tabular}

*: Significant at $P \leq 0.05$

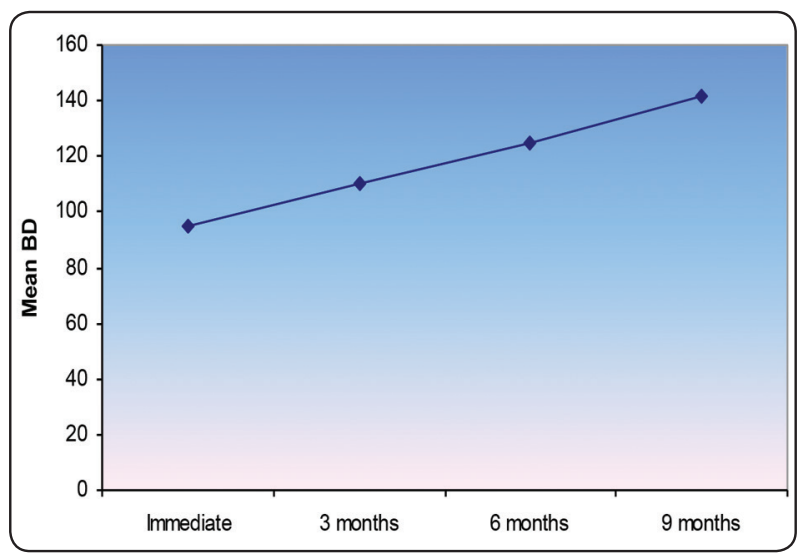

Fig. (25): Graph showing the change in bone density within the active group.

Through all periods, there was a statistically significant increase in mean bone density. This is due to after stabilization of blood clot in the defect underneath the lifted maxillary sinus membrane, bone formation started and continued with time. 


\section{Percentage changes}

TABLE (7): Mean, standard deviation (SD) values and results of Student's t-test for comparison between percentage changes in bone density of the two groups.

\begin{tabular}{|c|c|c|c|c|c|}
\hline \multirow{2}{*}{ Period } & \multicolumn{2}{|c|}{ Control } & \multicolumn{2}{c|}{ Active } & \multirow{2}{*}{ P-value } \\
\cline { 2 - 5 } & Mean & SD & Mean & SD & \\
\hline $\begin{array}{c}\text { Immediate }- \\
3 \text { months }\end{array}$ & 20 & 5.2 & 17.4 & 4.1 & 0.615 \\
\hline $\begin{array}{c}3 \text { months }- \\
6 \text { months }\end{array}$ & 11.4 & 4.3 & 15 & 7.1 & 0.402 \\
\hline $\begin{array}{c}6 \text { months }- \\
9 \text { months }\end{array}$ & 20.1 & 4.8 & 15.7 & 8.7 & 0.210 \\
\hline $\begin{array}{c}\text { Immediate }- \\
6 \text { months }\end{array}$ & 26.6 & 7.2 & 35.8 & 16.3 & 0.330 \\
\hline $\begin{array}{c}3 \text { months }- \\
9 \text { months }\end{array}$ & 10.5 & 4.5 & 29.5 & 8.7 & $0.018^{*}$ \\
\hline
\end{tabular}

$*$ : Significant at $P \leq 0.05$

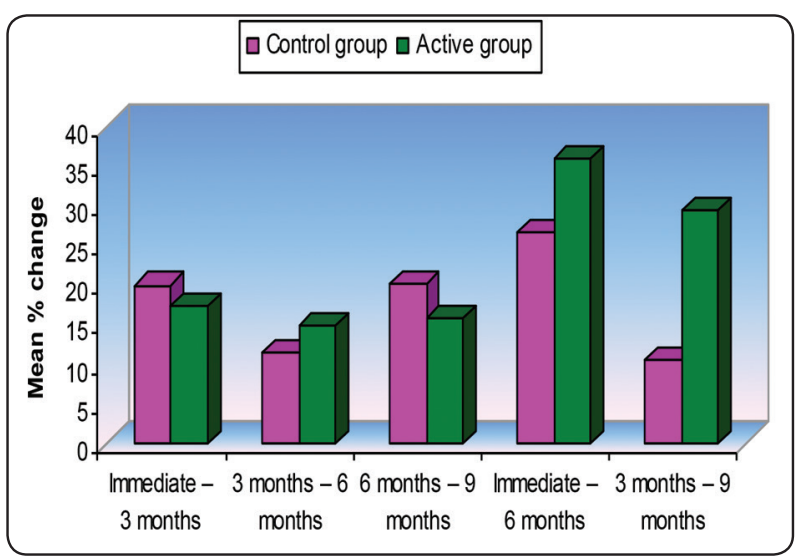

Fig. (26): Bar Chart comparing the percentage change in bone density between the two groups.

There was no statistically significant difference between mean $\%$ changes in bone density of the two groups through all periods except for the period (3 months - 9 months) where Active group showed statistically significantly higher mean $\%$ increase in bone density than control group. This is explained by the resorption that take place in the autogenous bone during the first three months post-surgical. Then resorption rate decrease and stabilization of the autogenous graft start to take place.

\section{DISCUSSION}

Dental implants have become one of the most challenging and rapidly developing topics in dental practice as nowadays they provide a proper treatment, alternative to conservative prosthodontics. However, in the posterior maxilla, anatomical limitations (such as deficiency of maxillary alveolar bone and increased pneumatization of the maxillary sinuses) constitute a challenging problem.

The candidates selected in this study had atrophied alveolar posterior maxillary ridge with sinus approximation that contradicts the use of conventional implantation procedure.

Twelve patients participated in this study. Male to female ratio was $1: 1$. Age range of the patient was 35-55 years, with a mean of 45 years. All the patients were selected free from any conditions that may complicate the surgical procedure or the healing process of the implant procedure. This was to avoid any systemic influence on bone formation or resorption.

Boyne and James ${ }^{(15)}$ described placement of a sinus floor bone graft by removal of a $1 \mathrm{~cm}$ in the lateral maxillary wall, reflection of the sinus membrane and placement of the graft through the bone defect. Kent and Block ${ }^{(16)}$ used other surgical technique by establishing a bony ceiling over the graft through infracturing the lateral wall of the maxilla. The lateral wall approach for grafting the maxillary sinus floor is much preferable than the technique described by Tatum ${ }^{(9)}$ in which the sinus floor was grafted through the alveolar crest (crestal approach). The crestal approach can only be used in case of presence of more than $8 \mathrm{~mm}$ in the residual alveolar bone. The present study utilized the lateral wall technique because it allows sufficient amount of the graft material to be introduced into the sinus, provides direct access to the sinus floor, and 
preserves the alveolar ridge. This is in agreement with many other studies..$^{9,16,17,18,19,20,21)}$ Additionally, this operation eliminates some of the complications associated with Caldwell -Luc procedure through preserving the epithelial lining of the maxillary sinus and the bony face of the maxilla. ${ }^{(22)}$

This study proved that sinus floor elevation with simultaneous implants placement is a successful procedure that could help in rehabilitation of severely resorbed maxilla. On the other hand, the two step procedure commonly performed: where the sinus floor elevation is carried out as a primary step, followed by placement of implant as a second step, is a time consuming procedure. Moreover, it may be unsuccessful for the physiologic changes that may occur in the sinus (pneumatization), which may make implant placement difficult again. Moreover, implant placement simultaneously adds good advantage of direct vision and support.

In this study the sinus floor elevation and antral augmentation by autogenous bone graft with simultaneous implantation was carried out to achieve stability for the implants. This study agrees with the opinion of Maiorana et $\mathrm{al}^{(23)}$ and Lundgren et $\mathrm{al}^{(24)}$ who decided that the maxillary sinus augmentation procedure is an internationally accepted method for rehabilitation with endosseous implants in atrophic posterior areas of the maxilla, as it is the least invasive and has low morbidity and can offer predictable success rates and has become a routine procedure as Merkx et $\mathrm{al}^{(26)}$ reported.

In this study, particulated autogenous bone was used for sinus augmentation. No failures were observed. This is in agreement with Isaksson, ${ }^{(8)}$ who reported that sinus augmentation with particulated bone have the least failure rate $(5 \%)$ as compared with other operations, ( onlay graft, le fort 1 ) where the failure rate was $15 \%$.

The technique of sinus floor elevation and subantral augmentation is one of the methods that allow improvement of vertical bone height in the anatomically unfavorable posterior maxilla, while having the objective of placing implants, either at the time of operation or after a certain healing period. Without this operation, primary stability of the implants often cannot be achieved because the alveolar crest is neither high nor wide

This study coincides with that of Mish ${ }^{(27)}$ and Raghoebar et al $^{(28)}$ who determined the available alveolar bone height for implant placement as $5 \mathrm{~mm}$ at least in the superior inferior direction, to allow the shoulder of the implants to be placed within it and be supported by the remaining alveolar bone, thus immediate stability of the implants and bone grafts were achieved. This was further emphasized by Babbush $^{(29)}$, Keller et $\mathrm{al}^{(20)}$ and Ulm et $\mathrm{al}^{(30)}$, who determined a minimum of $4-5 \mathrm{~mm}$ remaining between the crest of the residual alveolar ridge and the floor of the sinus for grafting with simultaneously implants placement to obtain primary stabilization of the implants.

In the present study cortico-cancellous particulate symphyseal autogenous bone graft was used for sinus augmentation. Autogenous bone graft has an osteogenic potential related to the number of surviving osteoblasts. The secretion of the osteoblasts activates osteo-induction, the differentiation of mesenchymal cells to osteoblasts, which is also brought about by the release of bone morphogenetic protein. Therefore new bone formation takes place in a faster rate due to the high osteoconductive quality of autogenous bone ${ }^{(17)}$. It was concluded that autogenous bone is regarded as the gold standard for nearly all bone grafting procedures, including the maxillary sinus floor $^{(32,33)}$. This is due to osteoinductive character of freshly obtained, vital autogenous bone, which will enhance graft consolidation, help maintain graft morphology and possibly improve long-term survival. ${ }^{(4,32,33,34,35,36,37)}$

The mandible is a convenient source of autogenous bone for alveolar reconstruction. In addition bone harvested from the mandible appears to have inherent biologic benefits, which have been 
attributed to its embryologic origin. ${ }^{(38,39,40,41)}$ The results of this study substantiates this statement where a statistically significant increase in the mean bone density throughout the follow up periods was observed.Jensen ${ }^{(32)}$ reported that autogenous bone grafts harvested from the mandible offer several advantages in the reconstruction of alveolar ridges for implant placement. The symphysis offers the potential for thicker grafts with an increased cancellous component and easy surgical access. These grafts require a short healing period and exhibit minimal resorption, while maintaining their dense quality. In addition these grafts eliminate the need to use an extra-oral donor site to obtain the needed bone and subject the patient to an extended period of hospitalization.

Bone formation observed around the implants indicated the success of osseointegration of the implants. Henry ${ }^{(37)}$ determined the success of an osseointegrated implants to be based in part on the clinical absence of mobility, lack of clinical inflammation and lack of a radiolucent area around the outline of the implant, (good hard and soft tissue acceptance).

In the active group where open sinus lifting was performed with simultaneous implant placement without grafting. The present study agree with Chen, ${ }^{(13)}$ Thor, ${ }^{(3)}$ who reported $100 \%$ bone formation around placed in lifted and non grafted maxillary sinus. Bone formation around all implants was statistically evident.

This study agrees with Chen et al. ${ }^{(13)}$ They evaluated the status of bone in patients subjected to maxillary sinus lifting and immediate implant placement with no graft material. In all 47 cases who received implants immediately after maxillary sinus lift without bone grafting, radiographic assessment proved that bone formation was evident to be filling all the gap in 9 months post surgical. No patients developed sinusitis or any other complications leading to implant loss. All 47 fixtures healed well, no infection or implant mobility was observed during initiation of loading.
As a matter of fact, the greatest advantage of this technique is the elimination of the morbidity of the donor site and increased patients acceptance.

Direct digital periapical radiography was employed in radiographic assessment as it is more standardized than the conventional radiography, eliminates the processing variations that could have affected the accuracy of the results, superior image quality, saving time of the processing and marked reduction in radiation exposure to the patient. Digital radiography was very useful for establishing the scope of the bone grafts and, indirectly, for assessment of its mineralization as reported by Mikołajczak et al. ${ }^{(38,39)}$

The radiographic technique used was the paralleling technique with an acrylic template which is a reliable technique for producing an accurate, precise and reproducible image of the same site at different follow up intervals. The exposure parameters were set to be fixed for every patient to ensure standardization for accurate results. ${ }^{(40)}$

Digital panoramic examination was performed in this study to assess the vertical dimension of bone, in order to select the proper implant length. The panoramic view is a quick, simple, lowcost and low-dose presurgical diagnostic tool and can be considered a safe preoperative evaluation procedure for routine posterior implant placement. When a safety margin of at least $2 \mathrm{~mm}$ is respected, panoramic radiography appears to be sufficient to evaluate available bone height prior to insertion of posterior implants. ${ }^{(41)}$

The results of the current study showed that the blood clot that forms underneath the maxillary sinus is capable of forming bone of comparable radio density to autogenous bone. In fact, six months post surgical, both groups showed similar radio densities.

During the first three months, the autogenous bone used in the control group was subjected to extensive resorption.This resorption was very rapid during this period. On the other hand, the active group showed very low radio density in the 
immediate post operative radiographs because only blood clot was filling the defect. After the first three months, the active group showed increase in the radio density because organization of the blood clot took place and bone formation was taking place. This is explained by the presence of autogenous bone graft in the control group, but in the active group, only blood is filling the defect.

During the second three months (3-6 months post surgical), Active group continued to show increase in bone density as bone formation was still in the buildup process. On the other hand, the control group showed decreased bone density as resorption continued. This is explained by resorption took place in the autogenous bone in the control group and on the other hand, bone formation was taking place in the active group. Therefore after three months from the date of surgery the mineralized tissue in both groups were within the same range.

During the last three months (6-9 months post surgical), the active group continued to show increase in bone density as bone buildup was taking place. In the control group, stabilization of the autogenous bone graft took place. Bone density showed marked increase in this group during this period. This is explained by the extended resorption in the autogenous bone graft versus bone formation in the active group. This is also explained by the extended resorption in the autogenous bone graft versus bone formation in the active group.

Several studies ${ }^{(42,43,44)}$ reported that penetration of the nasal or sinus cavities with titanium implants caused no complications during healing. Branemark et $\mathrm{al}^{(45)}$ explained that the reason for the lack of side effects with bone penetrating implants was believed to be the osseointegration of the implant itself, which means direct contact between the implant surface and the living bone tissue. This osseointegration creates a barrier to the migration of the microorganisms or the inflammatory cells along the implant. If the osseointegration didn't occur for some reason, but instead fibro-integration occurs, this would lead to migration of the inflammatory process.

In the present study, the sinus membrane was elevated from the sinus floor and its integrity was maintained throughout the surgical procedures except for minor perforation of one sinus membrane out of twelve. No signs or symptoms of infection involving the maxillary sinus or the graft tissue were observed in the follow up period. This could be attributed to the fact that very small perforations may be of little consequence and the membrane being redundant on its superior reflection, is usually self-sealing. ${ }^{(46,47)}$ This finding is in agreement with Reiser et $\mathrm{al}^{(48)}$ who reported that small sinus membrane perforations that happened during sinus membrane elevation did not affect the integrity of the membrane, the continuity of the operation and had no clinical significance, even more it had good prognosis without adverse effect on implant success. ${ }^{(49)}$

Altered sensation of the lower anterior teeth was relatively a less common postoperative symptom after symphyseal graft. In our study no case of altered sensation was detected due to the safe margin left away $(0.5-0.7 \mathrm{~mm})$ from the apices of the lower anterior teeth during harvesting the bone graft from the symphsis. Craig and Mish ${ }^{(50)}$, reported that almost one third of their patients with a symphyseal graft complained of dullness in sensation of the incisors. This feeling was resolved within 3 months and they recommend that $0.5 \mathrm{~mm}$ border should be left below the apices of the anterior teeth roots when bone is harvested from the chin to preserve contents of the incisive canal. Depending on sinus dimensions, enough bone can often be harvested from the symphysis to graft one sinus ${ }^{(44,51,52)}$.

Altered sensation of the lower lip and chin (temporary mental nerve parathesia) was further relatively less common postoperative symptom after symphyseal graft. In the present study 3 cases were detected where the sensory deficiency of lower lip and chin developed and began to improve after 
one month and completely resolved within three months. This finding coincide with Buhr et $\mathrm{al}^{(53)}$ who reported that almost one third of their thirty one cases with a symphyseal graft showed altered sensation of the lower lip and chin. Total resolution took place within 3 months.

In this study, radiographic evaluation in terms of change in bone density under the lifted maxillary sinus was performed using direct digital radiography and radiographic stent for standardization of the radiographic technique. The Digora software was used to analyze the results. Follow up visits were in intervals of one week post operative, three months, six months and nine months post operatively.

Comparable results were achieved between the two groups. This is because autogenous bone graft was subjected to extensive resorption during the first three months then it started to stabilize and only after six months it started to show marked increased mineralization. On the other hand, the blood clot in the active group was showing increased mineralization in terms of radio density from the beginning.

The results of the currentstudy prove that maxillary sinus lifting with simultaneous implant placement without any bone graft material is a reliable technique. In other words, bone graft is no more essential for grafting the maxillary sinus. The blood clot that organizes under the maxillary sinus is capable of forming bone, provided that a stable undisturbed blood clot is formed under the maxillary sinus. Also the presence of minor sinus perforations of less than five millimeters is of no significance on the final outcome of the procedure.

To summarize, bone grafting is no more essential in maxillary sinus lifting as it is subjected to extensive resorption during the first three months post operatively. As a matter of fact, blood clot is capable of forming bone of comparable radiodensity to that found in case of using autogenous bone graft.

\section{SUMMARY AND CONCLUSION}

Patients with atrophy in the posterior maxillary alveolar process and / or excessively pneumatized maxillary sinus are difficult to treat by conventional implant techniques due to lack of sufficient amount of alveolar bone to anchor the implant.

The present study includes twelve patients with atrophy of the posterior maxillary alveolar process and/or excessively pneumatized maxillary sinus. The male to female ratio was one to one with a mean age of 45 years. The cases were categorized into two equal groups. Group 1 (Control group) represent the control group where the sinus floor was elevated through the lateral approach and particulated symphesial bone graft was inserted. In group 2 (Active group), similarly the sinus floor was elevated through a lateral approach however, no graft was inserted. In both groups dental implants were immediately inserted. Clinical and radiographic follow up was carried out at 3,6 and 9 months postoperatively.

Autogenous bone from the chin, which is the gold standard for grafting, was compared to the use of no bone graft material to fill the defect under the lifted sinus membrane.

To conclude, sinus floor elevation through the lateral window approach with simultaneous implant placement as a one stage surgery is a reliable technique for rehabilitation of the atrophic posterior maxilla because it eliminates the morbidity of harvesting the donor site for bone graft collection. Additionally, such procedure can be performed under local anesthetic with minimal post operative pain and increased patient satisfaction. Moreover, this procedure decreases the time needed as compared to the two stages technique.

\section{CONCLUSION}

1- Maxillary sinus lifting and simultaneous implant placement as a one stage procedure is a reliable and predictable technique. 
2- The mandible offers a superior intra oral donor site for bone grafting. It have the least complications in terms of neurosensory affection, increased post operative pain and edema

3- Bone grafting is no more essential for grafting the maxillary sinus. Blood is capable of forming bone of comparable radio density to that found in case of using autogenous bone graft.

4- The morbidity of harvesting donor site for graft collection can now be avoided in cases of maxillary sinus lifting.

\section{REFERENCES}

1- Lancy WR,Talman DE,Keller EE, Dental implants: Tissue integrated ,Prosthesis utilizing the osseointegration concept. J. clin. Prosth. 61- 191 .1986.

2- Albrektosson T, Multicenters report on osseointegrated implants.J Prosth. Dent. 60-75 1988.

3- Thorwarth. Stability of autogenous bone grafts after sinus lift procedures.A comparative study between anterior and posterior aspects of the iliac crest and an intra oral donor site. J Oral surg Oral Pathol Oral Med Oral Radiol 2005100-278-84

4- Jensen J.,Krniz Simnon. Reconstruction of the severely atrophic maxilla with bone grafting and osseointegrated implants. J Oral and Maxillofacial Surg.48-27-32-1990.

5- Palmer RM, Floyed PD, Palmer PJ, Smith BJ, Albrektsson A. Healing of implant dehiscence with and without polytetra flouro-ethylene membrane. Clin. Oral Implants, 5-98104-1994

6- Pinholt EM, Haanaes HR, Donath EX. Titanium implants inerted in a dog augmented by allogenic material. Clin Oral Implants.5-213-219-1994.

7- Leonard DD, Pecora GE. Augmentation Of The Maxillary Sinus With Calcium Sulphate.Int J Oral Maxillo. Impl.14869-1999.

8- Issakson S, Alberius P.Osseous response to implanted natural bone mineral and synthetic hydroxyapatite ceramics in the repair of Skull Bone defects.J Oral And Maxillo Surg 50-241-1992.
9- Tatum H:Maxillary and inus reconstruction.Dent Clin North America 30-207-229-1986.

10- Collins T,Small S,Sinus floor elevations and the ststus of the membrane.Int J oral and Maxillo. Surg 85-96-1994

11- Lundgren S, Anderson S, Gualini F: Bone formation with sinus membrane elevation: A new surgical technique for maxillary sinus floor augmentation. Clinical Implant Dental Research 6:165, 2004

12- Kusiak J and Zins J. Early Revascularization of Membraneous Bone, Plastic Recon Surg. 24: 778, (1983).

13- Chen et al. Immediate implant placement with lateral approach for sinus lift without graft.Journal of oral and Maxillofacial Surgery 43-265- 2007.

14- Pinchasov G, Joudzbalys G: Graft free sinus augmentation procedure: a literature review. J oral Maxillofac Res. Apr 1;5(1) :e1/ jomr. 5101-2014

15- Boyen P J and James R A: Grafting of the maxillary sinus floor with autogenous marrow and bone. J Oral Surg. 38: 613; (1980).

16- Kent JN, Block MS.Simultaneous maxillary sinus grafting and insertion of implants and hydroxyapatite graft. J Oral Maxillo Implants.47-238-1989.

17- Johansson B,Wannfors K,Ekenbeck J,Smedberg JI. Implants and Sinus Inlay Bone Grafts in a 1 stage procedureon severely atrophied maxilla. Int J Oral and maxilla. Surg. 14-811-1999

18- Ueda M,Kaneda T. Maxillary sinusitis caused by dental implants .J Oral And Maxillo. Surg. 50-285-1992

19- Chavanaz M: Maxillary sinus: anatomy, physiology, surgery, and bone related to implantology, eleven years of surgical experience. J. Oral Implantology. 16: 199; (1990).

20- Keller EE, Echert SE and Tolman DE: Maxillary antral and nasal one - stage inlay composite bone graft: Preliminary report of 30 recipient sites. J. Oral Maxillofac. Surg. 52: 438; (1994).

21- Weigart D, Pertin G and Kalber J :Combined sinus lift procedure and lateral augmentation.A treatment comcept for the surgical and prosthodontic rehabilitation of atrophic maxilla.Int J Oral Maxillofac Surg 95-317-23-2005

22- Uckan S and Buch D : Sinus lift approach for retrieval of root fragments from the maxillary sinus. Int J Oral Maxillofac Surg 32-87-2003 
23- Maiorana C, Redemagni M, Rabagliati M and Salina S: Treatment of maxillary ridge resorption by sinus augmentation with iliac cancellous bone. Anorganic bovine bone, and endosseous implants: A clinical and histological report. Int. J. Oral Maxillofac. Implants. 15: 873; (2000).

24- Lundgren S, Moy P and Nilsson H: Augmentation of the maxillary sinus floor with particulated mandible.Int J Oral Maxilofac Implants.11-760-1996.1996

25- Merkx MW, Maltha JC and Stoelinga PJ: Assessment of the value of inorganic bone additives in sinus floor augmentation: a review of clinical reports Int. J. Oral Maxillofac.Surg.32:1(2003).

26- Isaksson S: Evaluation of three bone grafting techniques for severely resorbed maxillae in conjunction with immediate endosseous implants. Int. J. of Oral and Maxillofac. Implants. 9: 679; (1994).

27- Misch CE: Maxillary sinus augmentation for endosteal implants. Organized alternative treatment plans. Int. J. Oral Implantol.. 4:49; (1987).

28- Raghoebar GM, Batenburg PHK and Vissink A: Augmentation of localized defects of the anterior maxillary with autogenous bone before insertion of implants. J. Oral Maxillofac. Surg. 45: 1180-1158, (1996).

29- Babbush CA: Maxillary antroplasty with augmentation bone grafting. Dental Implants; the Art and Science. (2001)

30- Ulm C, Solar P, Blahout R, Matejka M and Gruber H: Reduction of the compact and cancellous bone substances of the edentulous mandible caused by resorption. Oral Surg. Oral Med. Oral Path. 74: 131; (1992).

31- Block MS, Kent JN, and Weinburg R. Bone Maintenance 5-10 years after sinus grafting.J Oral And Maxillo. Surg..56-6-1998.

32- Jensen J, Sindet-Pedersen S and Oliver AJ: Varying treatment trategies for reconstruction of maxillary atrophy with implants: Results in 98 patients. J. Oral Maxillofac. Surg. 52: 210-216, (1994)

33- Williamson RA: Rehabilitation of the resorbed maxilla and mandible using autogenous bone grafts and osseointegrated implants. Int. J. Oral Maxillofac. Implants 11; 476-488, (1996).

34- Raghoebar G M, Timmenga N M and Steggenga B: Maxillary bone graftinf for insertion of dental implants : Results after 12-124 months. Clin Oral Implants Res. 123-279-862001
35- Zins JE and Whitaker L: Membranous vs. endochondral bone: implications for craniofacial reconstruction, Plast. Reconstr. Surg. 72: 778, (1983).

36- Misch CM: Ridge autogenous mandibular bone grafts for reconstruction of ridge deficiencies prior to implant, Pract. Periodont. Aesthet. Dent. 8: 127-135 (1996).

37- Henry P J; Maxillofacial prosthetic consideration.Advanced osseointegration surgery.Chicago Quintessence 313-1992

38- Van der Stelt PF.Better imaging: the advantages of digital radiography.J Am Dent Assoc. ; 139 Suppl:7S-13S ,2008 .

39- Mikołajczak T, Wilk G, Gawrych E. Assessment of bone grafting mineralization in patients with alveolar clefts using digital radiography Ann Acad Med Stetin . ; 53(3):6673,2007

40- White SC, Pharoah MJ. Oral Radiology. Principles and interpretation. Fourth edition. Intraoral Radiographic Examinations. 8:122-68, Mosby, Inc, 2000.

41- Vazquez L, Saulacic N, Belser U, Bernard JP.Efficacy of panoramic radiographs in the preoperative planning of posterior implants: a prospective clinical study of 1527 consecutively treated patients.Clin Oral Implants Res. Jan; 19(1):81-85, 2008 .

42- Keller EE, Van Roekel NB, and Tolman D. Prosthetic urgical recinstruction of severely resorbed maxilla with iliac bone grafting and tissue integrated prosthesis. Int $\mathrm{J}$ Ora; Maxillo Implants 2-155,1987.

43- Jensen OT, Perkins S and Frank WV.Nasal fossa and maxillary sinus grafting of implants from a palatal approach. J Oral Maxillo. Surg.50-415,1992.

44- Misch CM, Misch CE, Resnik R and Ismail YH: Reconstruction of maxillary alveolar defects with mandibular symplhysis grafts for dental implants: a preliminary procedural report, Int. J. Oral Maxillofac. Implants 7 (3): 360361, (1992).

45- Branemark PI, An experimental and clinical study of osseointegrated implants penetrating the nasal cavity..J Maxillo Surg. 42-497,1984.

46- Sullivan.Uses of fibrin adhesives in sinus lift procedures. Oral Surg, Oral Med, Oral Path, Oral Radio.84-616,1997

47- Whitman D H.An autologous alternative to fibrin glue with application in maxillofacial surgery.J Oral Maxillofac. Surg 55-1294,1997. 
48- Reiser GM, Rabinovitz Z, Bruno J, Damoulis P D and Griffin T J: Evaluation of maxillary sinus membrane response following elevation with the crestal osteotome technique in human cadavers. Int. J. Oral Maxillofac. Implants. 6:833; (2001).

49- Cha HS, et al. Simultaneous sinus lift and implant installation: prospective study of consecutive two hundred seventeen sinus lift and four hundred sixty two implants. Clin implant Dent Relat Res :16(3);337-47,2014.

50- Craig M and Mish:Comparison of intraoral donor sites for grafting prior to implant placement.Int J Oral Maxillofac implants.12,767-776,1997
51- Borstlap W A, Heidbuchel KLWM and Kuijpers AM:Early econdry bone grafting of alveolar cleft defects.Comparison between chin and rib graft. J Craniomaxillofac Surg.18201-205,1990

52- Hoppenreites T J M and Freihofer H P M:The chin as a donor sitein early econdry osteoplasty.J Craniomaxillofac Surg.20-119-124-1992.

53- Buher W and Coulon JP: Limits of mandibular symphesis as a donor site for bone grafts in early secondary cleft palate osteoplasty.Int J Oral Maxillofac. Surg.25-389393,1996 . 